\title{
Microscopic analysis of plant-bacterium interactions using auto fluorescent proteins
}

\author{
Guido V. Bloemberg
}

Received: 22 January 2007/Accepted: 7 May 2007/Published online: 12 June 2007

(C) KNPV 2007

\begin{abstract}
Plant growth promoting rhizobacteria (PGPR) include bacteria that fix nitrogen (e.g., Rhizobiaceae, Herbaspirillum, Azoarcus), produce phytohormones (e.g., Azospirillum) and provide protection against fungal and/or bacterial pathogens (e.g., Pseudomonas, Bacillus, Streptomyces). Interactions between PGPR and plants can be divided into different steps which include initial attraction, attachment, proliferation and colonization e.g., of roots, stem, leaves and flowers. At the genetic level the expression of many bacterial genes are altered during these processes. In addition to the interaction with the plant, PGPR interact and compete with the endogenous microflora, consisting of other bacteria, fungi and/or mycorrhizal fungi. In the case of biocontrol bacterial strains, a direct interaction with the pathogen is often required to suppress the disease. Microscopic analyses of plant growth promoting rhizobacteria (PGPR) in their natural environment and in specific during their interaction(s) with the host plant(s) and/or their target organism(s) is essential for the elucidation of their functioning and the successful application of commercial inoculants. With the discovery and development of auto fluorescent proteins (AFPs) as markers and the development of highly sophisticated fluorescence microscopes such as confocal laser
\end{abstract}

G. V. Bloemberg $(\bowtie)$

Institute of Biology, Leiden University, Wassenaarseweg 64, 2333AL Leiden, The Netherlands

e-mail: g.v.bloemberg@biology.leidenuniv.nl scanning microscopes, a new dimension has been created for studying PGPR in their natural environment. This paper will give a short overview on available tools, the application of AFPs in PGPR research and some future perspectives. Several recent reviews will give the reader an option for further reading (Bloemberg and Lugtenberg 2004; Chalfie and Kain 2005; Larrainzar et al. 2005; Rediers et al. 2005; Bloemberg and Camacho 2006).

Keywords PGPR - Auto fluorescent proteins - GFP . Microscopy $\cdot$ Marker proteins $\cdot$ Plant-microbe interactions

\section{A short overview of available auto fluorescent proteins and their properties}

The first application of green fluorescent protein (GFP) isolated from the jellyfish Aequorea victoria as a reporter (Chalfie et al. 1994) has become a hallmark in modern biology and is used throughout a wide range of different biology and biotechnology research areas including many fields of microbiology and cell biology. AFPs have become the most important reporters providing new tools to mark whole cells, study protein localization, and monitor gene expression and molecule interactions in vivo in a non-invasive way thereby preserving the integrity of the cell. Advantages of the use of GFP in comparison with other reporters or dyes is that GFP is present within the cell as a product of 
gene expression and that the visualization does not require any fixation or preparation protocols, which are time-consuming and might result in artifacts or influence cellular properties. Furthermore it does not require substrates or additional energy such as often is the case in bioluminescence. Additional advantages are that GFP due to its tertiary barrel structure is very stable and can be applied in many different species. In addition, GFP labelled cells can be used for flow cytometry analysis and quantitative analysis by PCR (Utermark and Karlovsky 2006). Disadvantages of GFP are that its structure and fluorescence is dependent on $\mathrm{pH}$ and the presence of oxygen (Heim et al. 1994). However, studies on Rhizobium tagged with a GFPderivative showed that GFP was well visualized in bacteroids present in root nodules, which is an oxygenlimiting environment (Gage et al. 1996; Stuurman et al. 2000). Since GFP is not an enzyme it does not have amplifying reporter ability, such as, for example, LacZ. Successful GFP visualization is therefore a balance between sufficient production and prevention of overproduction that could cause toxicity or a metabolic burden to the cell resulting in growth inhibition. The latter should be tested for each bacterial species. Cloning of $e$-gfp under control of the lac promoter on a high copy number plasmid in E.coli results, for instance, in a severe growth inhibition when grown on Luria-Bertani agar medium (unpublished results). After 2 days of incubation white colonies grow out of the bacterial streak representing spontaneous $g f p$ mutants with a growth advantage. Another point of consideration before applying GFP is the autofluorescence background or noise from the environment in which the bacteria are to be analysed. For example, sand and other soil particles can severely hamper GFP visualization as well as certain plant structures or organelles such as chloroplasts. Such problems might be solved by using other auto fluorescent proteins with different excitation and emission wavelength spectra.

Modifications of GFP (often by gene shuffling experiments) have resulted in the isolation of mutants that have shifted emission and excitation wavelengths, which give the opportunity to use multiple auto fluorescent proteins in one system in order to differentiate between different cells or to visualize different processes within one cell. In addition, such variants are also brighter and more stable. Important GFP derivatives are Enhanced GFP (EGFP), Enhanced Cyan Fluorescent Protein (ECFP) and Enhanced
Yellow Fluorescent Protein (YFP) (Yang et al. 1998; Tsien 1998; Matus 1999; Ellenberg et al. 1999). Blue fluorescent protein (BFP) has also been developed but is less used due to its low brightness. In addition many other $g f p$ derivatives have been isolated or developed with enhanced brightness and optimized codon usage for optimal expression in different organisms. A wide range of auto fluorescent proteins with useful background information is available on the website of the Clontech company (http://www.clontech.com/). Although the stability of GFP is very advantageous for tracking studies, it hampers transient gene expression studies. Andersen et al. (1999) have developed a set of GFP derivatives with reduced half-lifetimes by the addition of short amino acid tags to the C-terminus, recognized by specific proteases widely present in bacterial cells, which usually break down partially produced proteins.

Although many efforts were made to isolate a red fluorescent derivative of GFP, this has never been achieved and was bypassed by the discovery and application of Red Fluorescent Protein (RFP or DsRed) isolated from the coral Discosoma striata (Matz et al. 1999). Since the $r f p$ sequence is not homologous to $g f p$ the use of both genes in one cell will not result in unwanted recombinations. An efficient use of DsRed is hampered by its slow maturation due to its tetramerization, which is required for its fluorescent properties, and its toxic properties when overproduced. Recently, several improved DsRed derivatives have been constructed to overcome these problems. One of these new derivatives DsRed.T3_S4T, which maturates faster (Sorensen et al. 2003) was successfully applied in Pseudomonas spp. for rhizosphere studies in being brighter and without causing loss of competitive colonization ability (Dandie et al. 2005). A more recent paper by Shaner et al. (2004) reports on the construction of improved monomeric red, orange and yellow fluorescent proteins derived from DsRed, which mature more efficiently, are more tolerant to N-terminal fusions and have an improved photostability. These forms have not been reported for studies of PGPR.

\section{Genetic tools to mark microorganisms with auto fluorescent proteins}

A requirement of the application of AFPs is that the genes encoding these proteins have to be transformed 
into the bacteria. This requirement can prevent the use of GFP as a marker when a certain bacterial species or strain is not genetically accessible with the available transformation protocols. AFP genes are usually delivered on plasmids or transposons (Bloemberg et al. 2004). The advantage of a plasmid is that it is present in multiple copies, which can improve the production of AFPs and does not disrupt host genes by chromosomal integration.

Since antibiotics cannot usually be applied for in vivo studies of PGPR on the plant the development of a set of broad host range plasmids that are stably maintained (in Gram-negative bacteria) without antibiotic pressure has been extremely valuable (Heeb et al. 2000). We have used such plasmids to construct a set of marker plasmids carrying egfp (green), ecfp (cyan), eyfp (yellow) ebfp (blue) and $r f p$ (red), which were successfully used for the visualisation of PGPR such as Pseudomonas biocontrol strains and Rhizobium strains respectively (Stuurman et al. 2000; Bloemberg et al. 2000). The value of these vectors was also shown for the analysis of the improved DsRed form (Dandie et al. 2005). Another point of attention for an efficient marking is the use of an appropriate promoter. Both the use of a tac and lac promoter were shown successful for the constitutive expression of AFPs in Pseudomonas and Rhizobium and many other Gram-negative bacterial strains (Bloemberg et al. 1997, 2000) (Fig. 1). During the past 10 years valuable transposon constructs have also become available, that carry mainly $g f p$ derivatives for marking and/or gene expression studies (Burlage et al. 1995; Tombolini et al. 1997; Unge et al. 1997; Xi et al. 1999).

Since fungi are frequently part of the endogenous microflora and can even be the direct target for the PGPR effect as in case of biological control, it is of great relevance to tag fungi and study their interaction with the PGPR. However, genetic transformation of fungi is usually more difficult than transformation of bacterial cells, due to the presence of the rigid cell wall and need for stable integration of genetic material in the chromosome. A classic method consists of the preparation of protoplasts, which will subsequently take up genetic material, mostly in the form of plasmids, which will integrate into the chromosome. Consequently, fungal transformants have to be tested for the conservation of phenotypic properties such as morphology, growth and pathogenicity before using these transformants in confrontation studies. Using an optimized protoplast transformation protocol we have tagged Fusarium oxysporum f.sp. radicis lycopersici with different autofluorescent proteins by co-transformation with two plasmids of which one contained a hygromycin resistance gene and the second an afp gene (Lagopodi et al. 2002; Bolwerk et al. 2003). In addition to protoplastation methods, fungi can be transformed by ballistic bombardment and more recently by the transformation ability of Agrobacterium (de Groot et al. 1998), which has been shown to be a simple, efficient and successful transformation method for many fungi (Michielse et al. 2005).

\section{Some examples of the use of auto fluorescent proteins for the visualization of PGPR in the plant environment}

Initial studies using auto fluorescent proteins (in specific GFP) as markers for PGPR were used for localization studies. Most of these studies showed that PGPR and other microorganisms such as phytopathogenic fungi preferentially colonize the junctions between the root cells (Bloemberg et al. 1997, 2000; Tombolini et al. 1999; Lagopodi et al. 2002; Bolwerk et al. 2003; Gamalero et al. 2005) (Fig. 1). Most steps in the symbiosis process between Rhizobiacea and leguminous plants occur inside the root after entrance into the infection thread. The use of GFP has allowed us to visualize the process of attachment, entrance and nodule occupancy in great detail (Gage et al. 1996) making it even possible to determine the growth rate of the cells in the infection thread (Gage et al. 1996). Stuurman et al. (2000) showed that GFP tagged Rhizobium bacteroids move in the root nodule. Since the root is sometimes too thick for successful imaging due to loss of light in the deeper root parts, sectioning of the plant material can solve this. This is also used for the study of endophytes as was shown by several publications on Herbaspirillum spp. (Elbeltagy et al. 2001) and the pathogen invasion of Xylella fastidiosa (Newman et al. 2003). When necessary plant material can also be stored before visualization by fixation with paraformaldehyde, which leaves GFP intact for fluorescent studies (Stuurman et al. 2000; Elbeltagy et al. 2001). Confocal laser scanning microscopy (CLSM) analysis of the colonization behaviour of afp-tagged antagonistic strains can also provide important information on the sampling strategy 

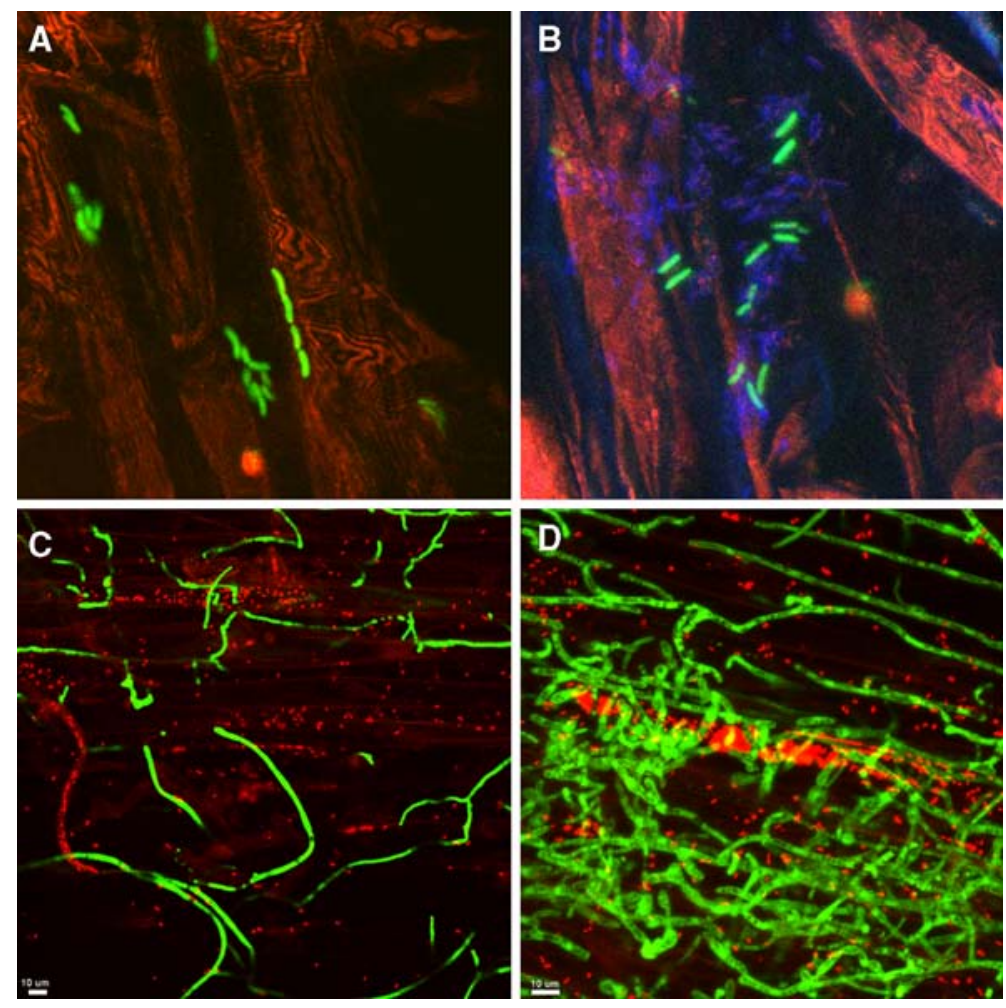

Fig. 1 Confocal laser scanning microscopy (CLSM) analyses of Pseudomonas biocontrol strains and the pathogen Fusarium oxysporum f.sp. radicis lycopersici marker with auto fluorescent proteins in the tomato rhizosphere. Panels (A) $P$. fluorescens WCS36 marked with Green Fluorescent Protein (GFP) on the tomato root surface; (B) Colonies of $P$. fluorescens WCS365 after inoculation of a mixed culture

of GFP and cyan fluorescent protein (CFP) marked derivative strains; (C and D) Simultaneous imaging of P. fluorescens WCS365 marked with red fluorescent protein (DsRed) and Fusarium oxysporum f.sp. radicis lycopserisci marked with GFP. (images were produced by A. Wijfjes, A. Lagopodi and A. Bolwerk)

required for monitoring inoculant strains and combine these with data on the kinetics of the endogenous microflora (Gotz et al. 2006).

Localization studies are also valuable for the analysis of the properties of mutant strains, for instance for their adhering abilities. For example Biancotto et al. (2001) showed by using mucoid mutant strains of $P$. fluorescens CHA0, that acidic extracellular polysaccharides (EPS) are an important factor in adhesion to roots and fungi.

The ability to mark cells with different AFPs makes it possible to visualize simultaneously different species and populations. We have shown that it is possible to distinguish three different populations of $P$. fluorescens WCS365 cells tagged with ecfp, egfp and $r f p$ simultaneously in the rhizosphere (Bloemberg et al. 2000). By looking at the ratios of differentially tagged cells present within the microcolonies it is

suggested that most colonies are initiated by a single cell after which other cells from outside can still join the colony later in time as they will also leave colonies to colonize other parts of the root (Bloemberg et al. 2000). When visualizing two different organisms or populations a combination of GFP and DsRed (preferentially the improved forms) is most deficient since their spectra hardly overlap. Studies using mixed populations of two species, e.g., P. chlororaphis PCL1391 and P. fluorescens WCS365 showed that mixed colonies were formed, which were mostly present on the upper root part and that $P$. chlororaphis had a preference for colonizing the root hairs (Dekkers et al. 2000). The study of bacterial communities is also important to understand collaborations between bacteria as shown for instance for P. putida strains that are able to degrade polyaromatic hydrocarbons, which is stimulated by the presence of 
polyaromatic hydrocarbons suggesting that sensing processes, such as chemotaxis, are involved (Kuiper et al. 2002). Studies on phase variation of Pseudomonas brassicacearum, in which Phase I cells were labelled with GFP and Phase II cells with DsRed showed that Phase I and II cells colonize different niches on the root of Arabidopsis thaliana (Achouak et al. 2004). Whereas Phase I cells were mostly observed at the basal part of the root, Phase II cells were observed at secondary roots and root tips, which can be explained by the fact that Phase II cells make flagellin and are more motile. Also competition studies have been performed other than for Pseudomonas spp. such as for $S$. meliloti populations for which it was shown that mixed populations can be present in infection threads, which subsequently can result in mixed populations in the root nodule (Gage 2002).

Another valuable possibility for dual imaging is the visualization between biocontrol agents and phytopathogenic fungi that they control. After visualization of the infection process of Fusarium oxysporum f.sp. radicis lycopersici marked with GFP on tomato resulting in tomato foot and root rot (Lagopodi et al. 2002) interactions between Pseudomonas biocontrol species (tagged with $r f p$ ) and Fusarium were performed to obtain a better fundamental understanding of their interactions in the rhizosphere (Bolwerk et al. 2003) (Fig. 1, panels C and D). These studies showed that Pseudomonas and Fusarium compete for the colonization of same niches (intercellular junctions) and directly interact with each other. At sites where bacteria were present, infection of the root by penetration of Fusarium was not observed. In addition, Pseudomonas attached to the Fusarium hyphae and were able to extensively colonize those hyphae similar to what was observed during in vitro confrontation assays (Bolwerk et al. 2003). Molecular mechanisms involved in the attachment and colonization of the hyphae are hardly known. In the presence of P. chlororaphis PCL1391 many stress responses of the Fusarium were observed such as loss of growth directionality, increased vacuole formation, curly growth, swollen bodies and increased branching. It was shown that the antifungal compound produced by $P$. chlororaphis strain PCL1391 is (partially) responsible for these stress effects. We have also used GFP and CFPexpressing Fusarium strains to visualize the effect of biocontrol strains on $F$. oxysporum. Studies using $g f p$ labelled Trichoderma atroviride and the (nonlabelled) phytopathogenic fungi Pythium ultimum and Rhizoctonia solani on cucumber seeds showed that $T$. atroviride reacted to the presence of these pathogens by increased branching and the formation of morphological changes similar to hooks, appressoria, and papillae (Lu et al. 2004). AFPs will be an important tool for further elucidation of the molecular mechanisms involved in bacterium-fungus interactions.

\section{Auto fluorescent proteins applied as tools for the visualization of ecological processes}

Besides the purpose of localization of bacterial cells in their environment, auto fluorescent proteins are progressively used for other applications such as gene expression analysis, biosensor reporter systems, identification of specific environmental expressed genes and analysis of horizontal gene transfer in the environment.

The instable GFP variants made by Andersen et al. (1999) facilitate the analysis of transient gene expression in the rhizosphere. For instance, they were used to monitor the ribosomal activity of $P$. putida cells (Ramos et al. 2000). More recently, they were applied for the monitoring of anti-fungal metabolite production by the biocontrol agent $P$. fluorescens CHA0 (Baehler et al. 2005). Promoter regions of the biosynthetic genes of the three antifungal metabolites produced by CHA0, e.g., 2,4-diacetylphloroglucinol (DAPG), pyoluteorin (PLT) and pyrrolnitrin (PRN), were fused to GFP and their expression kinetics analysed in vitro. It will be exciting to apply these constructs in the rhizosphere and in the presence of fungi to analyze the influence of the fungus on the expression of the anti-fungal metabolite genes.

Stable GFP can also be used for expression studies in order to show that a gene of interest is expressed under certain conditions, without being able to analyze the transient expression profile. For example, it was shown by Rothballer et al. (2005) that the ipdC gene of Azospirillum brasilense, which is involved in indole-3-acetic acid production, is indeed expressed in the wheat rhizoplane. Other GFP-based expression systems were constructed to learn more about the direct interaction between the plant and the bacterium 
and the conditions that bacteria encounter in the rhizo- and phyllosphere. For example Leveau and Lindow (2001) applied an expression system that showed that the use of sugars, e.g., fructose and/or sucrose is mainly responsible for the growth of Erwinia herbicola on bean leaves. The construction and application of two bacterial sensors for the detection of nitrate availability indicated that roots compete for nitrate with the microbial rhizosphere population (DeAngelis et al. 2005). Studies on thiamine synthesis $g f p$ reporter systems in Rhizobium leguminosarum bv. viciae showed that the rhizosphere of vetch and pea is poor in thiamine and that thiamine production is induced in the rhizosphere (Karunakaran et al. 2006). Another GFP-based study by Aldon et al. (2000) showed that physical contact between the bacterial cell and the plant strongly induces the expression of the hrp genes. The use of bioreporters has significantly contributed to the fundamental understanding of how bacteria interact with the plant (Leveau and Lindow 2002).

The development of GFP-based biosensor systems for the detection of AHL production were used to show that AHLs are produced in the microcolonies present in the rhizosphere, which will enable crosstalk between species in the rhizosphere (Andersen et al. 2001; Steidle et al. 2001).

A real challenge for researchers is to identify genes that are specifically expressed in the natural environment in order to understand the functioning of bacteria in their natural environment and to elucidate novel processes. In vivo expression technology is an elegant and powerful example of how environmentally-expressed genes can be identified (Rediers et al. 2005). In addition, other systems have been developed such as differential fluorescence induction (DFI) and optical trapping microscopy (Allaway et al. 2001), which for example allowed the identification of a rhizosphere-specific putative $\mathrm{ABC}$ transporter of putrescine (Allaway et al. 2001). Further development of systems for promoter trapping will facilitate the identification of other plant-associated genes (Izallalen et al. 2002).

When dual fluorescence imaging systems are not available, reporter systems based on two different techniques were shown to be of great value. For example, constructs carrying gfp and gusA in miniTn5 transposons (Xi et al. 1999) or plasmids (Ramos et al. 2002) were applied for the imaging of
Azospirillum brasilense on wheat roots. These analyses showed that high concentrations of Azospirillum were present in the intercellular root cell spaces and at points of lateral root emergence, which are niches where nutrients presumably leak out of the root (Xi et al. 1999; Ramos et al. 2002). Other examples of combined reports are the use of immunofluorescence and a rRNA-targeting probe, which was used to analyze $P$. fluorescens DR54 in the sugar beet rhizosphere, showing that most metabolically active cells are found at the root tip and that endogenous soil microorganisms start colonizing the rhizosphere 2 days after seed inoculation (Lübeck et al. 2000). Another way to analyze metabolic activity is the use of luciferase, the activity of which is dependent on the cellular energy level. In combination with GFP, a construct containing $\operatorname{lu} x A B$ genes was applied for $P$. fluorescens SBW25 showing that SBW25 was metabolically active in the whole rhizosphere (Unge et al. 1999; Unge and Jansson 2001), which can explain why the rhizosphere of wheat is more extensively colonized than, for example, the tomato rhizosphere.

As a last example I want to draw attention to recent work published by Molbak et al. (2006), in which horizontal gene transfer in the rhizosphere of pea and barley was analysed by CLSM studies. For that purpose they used $P$. putida KT2442 carrying a plasmid expressing $g f p$, which could be received by $P$. putida LM24 expressing dsRed. Their studies showed that plasmid transfer in the rhizosphere is determined by cell density and cell distribution, which are determined by exudation and root growth.

\section{Future prospects}

The application of auto fluorescent proteins will make a continuous contribution to the understanding of how PGPR function during their beneficial interactions with the plant and the endogenous microflora. Studying the molecular basis of the interactions between fungi and bacteria is an emerging field with great relevance in plant microbiology. Future studies will highly benefit from the developed tools for visualization of these organisms.

Acknowledgements I thank the microbiology group of the Institute of Biology Leiden (IBL) at Leiden University for 
fruitful discussions, their enthusiasm and results produced. I thank Gerda Lamers of the IBL microscopy unit for her valuable advise on the optimal use of confocal laser scanning microscopy and her technical assistance.

\section{References}

Achouak, W., Conrod, S., Cohen, V., \& Heulin, T. (2004). Phenotypic variation of Pseudomonas brassicacearum as a plant root-colonization strategy. Molecular Plant Microbe Interactions, 17, 872-879.

Aldon, D., Brito, B., Boucher, C., \& Genin, S. (2000). A bacterial sensor of plant cell contact controls the transcriptional induction of Ralstonia solanacearum pathogenicity genes. EMBO Journal, 19, 2304-2314.

Allaway, D., Schofield, N. A., Leonard, M. E., Gilardoni, L., Finan, T. M., \& Poole, P. S. (2001). Use of differential fluorescence induction and optical trapping to isolate environmentally induced genes. Environmental Microbiology, 3, 397-406.

Andersen, J. B., Heydorn, A., Hentzer, M., Eberl, L., Geisenberg, O., Christensen, B. B., Molin, S., \& Givskov, M. (2001). Gfp-Based $N$-acyl homoserine-lactone sensor systems for detection of bacterial communities. Applied and Environmental Microbiology, 67, 575-585.

Andersen, J. B., Sternberg, C., Poulsen, L. K., Bjorn, S. P., Givskov, M., \& Molin, S. (1999). New unstable variants of green fluorescent protein for studies of transient gene expression in bacteria. Applied and Environmental Microbiology, 64, 2240-2246.

Baehler, E., Bottiglieri, M., Pechy-Tarr, M., Maurhofer, M., \& Keel, C. (2005). Use of green fluorescent protein-based reporters to monitor balanced production of antifungal compounds in the biocontrol agent Pseudomonas fluorescens CHA0. Journal of Applied Microbiology, 99, 24-38.

Biancotto, V., Andreotti, S., Balestrini, R., Bonfante, P., \& Perotto, S. (2001). Extracellular polysaccharides are involved in the attachment of Azospirillum brasilense and Rhizobium leguminosarum to arbuscular mycorrhizal structures. European Journal of Histochemistry, 45, 39-49.

Bloemberg, G. V., \& Camacho, M. (2006). Microbial interactions with plants; a hidden world? In: B. Schultz, C. Boyle \& T. Sieber (Eds.), Soil biology, volume 9, microbial root endophytes (pp. 321-336). Heidelberg: Springer Verlag Berlin.

Bloemberg, G. V., Lagopodi A., de Bruijn, F. J., \& Jansson, J. K. (2004). Visualisation of microbes and their interactions in the rhizosphere using auto fluorescent proteins as markers. In: G. A. Kowalchuk, F. J. de Bruijn, I. M Head, A. D. Akkermans \& J. D. v. Elsas (Eds.), Molecular microbial ecology manual (pp. 1257-1280). Heidelberg: Springer Berlin.

Bloemberg, G. V., \& Lugtenberg, B. J. J. (2004). Biofilm formation on plants, their relevance and phenotypic aspects. In: Ghannoum, \& G. O'Toole (Eds.). Microbial biofilms (pp. 141-159). Washington, D.C.: ASM press.

Bloemberg, G. V, Wijfjes, A. H. M., Lamers, G. E. M., Stuurman, N., \& Lugtenberg, B. J. J. (2000). Simultaneous imaging of Pseudomonas fluorescens WCS365 populations expressing three different autofluorescent proteins in the rhizosphere; new perspectives for studying microbial communities. Molecular Plant Microbe Interactions, 13, 1170-1176.

Bloemberg, G. V., O’Toole, G., Lugtenberg, B. J. J., \& Kolter, R. (1997). Green fluorescent protein as a marker for Pseudomonas spp. Applied and Environmental Microbiology, 63, 4543-4551.

Bolwerk, A., Lagopodi, A. L., Wijfjes, A. H. M., Lamers, G. E. M., Chin-A-Woeng, T. F. C., Lugtenberg, B. J. J., \& Bloemberg, G. V. (2003). Interactions in the tomato rhizosphere of two Pseudomonas biocontrol strains with the phytopathogenic fungus Fusarium oxysporum f. sp. radicis-lycopersici. Molecular Plant-Microbe Interactions, 16, 983-993.

Burlage, R. S., Yang, Z. K., \& Mehlhorn, T. (1995). A transposon for green fluorescent protein transcriptional fusions: Applications for bacterial experiments. Gene, 173, 53-58.

Chalfie M., Kain S. R. (Eds.) (2005). Green fluorescent protein: Properties, applications and protocols (Methods of Biochemical Analysis, Vol 47). New York: Wiley.

Chalfie, M., Tu, Y., Euskirchen, G., Ward, W. W., \& Prasher, D. C. (1994). Green fluorescent protein as a marker for gene expression. Science, 263, 802-805.

Dandie, C. E., Larrainzar, E., Mark, G. L., O’Gara, F., \& Morrisey, J. P. (2005). Establishment of DsRed.T3_S4T as an improved autofluorescent marker for microbial ecology applications. Environmental Microbiology, 7, 1818-1825.

DeAngelis, K. M., Ji, P., Firestone, M. K., \& Lindow, S. E. (2005). Two novel bacterial biosensors for detection of nitrate availability in the rhizosphere. Applied and Environmental Microbiology, 71, 8537-8547.

de Groot, M. J., Bundock, P., Hooykaas, P. J., \& Beijersbergen, A. G. (1998). Agrobacterium tumefaciens-mediated transformation of filamentous fungi. Nature Biotechnology, 16, 839-842.

Dekkers, L. C., Mulders, I. H., Phoelich, C. C., Chin-A-Woeng, T. F. C., Wijfjes, A. H. M., \& Lugtenberg, B. J. J. (2000). The sss colonization gene of the tomato-Fusarium oxysporum f.sp. radicis lycopersici biocontrol strain Pseudomonas fluorescens WCS365 can improve root colonization of other wild-type Pseudomonas spp. bacteria. Molecular Plant Microbe Interactions, 13, 1177-1183.

Elbeltagy, A., Nishioka, K., Sato, T., Suzuki, H., Ye, B., Hamada, T., Isawa, T., Mitsui, H., \& Minamisawa, K. (2001). Endophytic colonization and in planta nitrogen fixation by a Herbaspirillum sp. isolated from wild rice species. Applied and Environmental Microbiology, 67, 5285-5293.

Ellenberg, J., Lippincott, S. J., \& Presley, J. F. (1999). Dualcolour imaging with GFP variants. Trends in Cell Biology, 9, 52-56.

Gage, D. J. (2002). Analysis of infection thread development using Gfp- and DsRed-expressing Sinorhizobium meliloti. Journal of Bacteriology, 184, 7042-7046.

Gage, D. J., Bobo, T., \& Long, S. R. (1996). Use of green fluorescent protein to visualize the early events of symbiosis between Rhizobium meliloti and alfalfa (Medicago sativa). Journal of Bacteriology, 178, 7159-7166.

Gamalero, E., Lingua, G., Tombolini, R., Avidano, L., Pivato, B., \& Berta, G. (2005). Colonization of tomato root seedling by Pseudomonas fluorescens 92 rkG5: Spatio- 
temporal dynamics, localization, organization, viability, and culturability. Microbial Ecology, 50, 289-297.

Gotz, M., Gomes, N. C., Dratwinski, A., Costa, R., Berg, G., Peixoto, R., Mendonca-Hagler, L., \& Smalla, K. (2006). Survival of $g f p$-tagged antagonistic bacteria in the rhizosphere of tomato plants and their effects on the indigenous bacterial community. FEMS Microbiology Ecology, 56, 207-218.

Heeb, S., Itoh, Y., Nishijyo, T., Schnider, U., Keel, C., Wade, J., Walsh, U., O'Gara, F., \& Haas, D. (2000). Small, stable shuttle vectors based on the minimal pVS1 replicon for use in gram-negative, plant-associated bacteria. Molecular Plant-Microbe Interactions, 13, 232-237.

Heim, R., Prasher, D. C., \& Tsien, R. Y. (1994). Wavelength mutations and post-translational autoxidation of green fluorescent protein. Proceedings National Academy of Sciences USA., 91, 12501-12504.

Izallalen M., Levesque, R. C., Perret, X.., Broughton, W. J., \& Antoun, H. (2002). Broad-host-range mobilizable suicide vectors for promoter trapping in gram-negative bacteria. Biotechniques, 33, 1038-1043.

Karunakaran, R., Ebert, K., Harvey, S., Leonard, M. E., Ramachandran, V., \& Poole, S. P. (2006). Thiamine is synthesized by a salvage pathway in Rhizobium leguminosarum bv. viciae strain 3841. Journal of Bacteriology, 188, 6661-6668.

Kuiper, I., Kravchenkov, L., Bloemberg, G. V., \& Lugtenberg, B. J. J. (2002). Pseudomonas putida strain PCL1444, selected for efficient root colonization and naphthalene degradation, effectively utilizes root exudates components. Molecular Plant Microbe Interactions, 15, 734741.

Lagopodi, A. L., Ram, A. F. J., Lamers, G. E. M., Punt, P. J., van den Hondel, C. A. M. J., Lugtenberg, B. J. J., \& Bloemberg, G. V. (2002). Confocal laser scanning microscopical analysis of tomato root colonization and infection by Fusarium oxysporum f.sp. radicis-lycopersici using the green fluorescent protein as a marker. Molecular Plant Microbe Interactions, 15, 172-179.

Larrainzar, E., O’Gara, F., \& Morrisey, J. P. (2005). Applications of autofluorescent proteins for in situ studies in microbial ecology. Annual Review of Microbiology, 59, 257-277.

Leveau, J. H., \& Lindow, S. E. (2001). Appetite of an epiphyte: Quantitative monitoring of bacterial sugar consumption in the phyllosphere. Proceedings of the National Academy of Sciences USA, 98, 3446-3453.

Leveau, J. H., \& Lindow, S. E. (2002). Bioreporters in microbial ecology. Current Opinion in Microbiology, 5, 259-265.

Lübeck, P. S., Hansen, M., \& Sørensen, J. (2000). Simultaneous detection of the establishment of seed-inoculated Pseudomonas fluorescens strain Dr54 and native soil bacteria on sugar beet root surfaces using fluorescense antibody and in situ hybridization techniques. FEMS Microbiology Ecology, 33, 11-19.

Lu, Z., Tombolini, R., Woo, S., Zeilinger, S., Lorito, M., \& Jansson, J. K. (2004). In vivo study of trichoderma-pathogen-plant interactions, using constitutive and inducible green fluorescent protein reporter systems. Applied and Environmental Microbiology, 70, 3073-3081.
Matus, A. (1999). GFP in motion CD-ROM - Introduction: GFP illuminates everything. Trends in Cell Biology, 9, 43.

Matz, M. M. V., Fradkov, A. F., Labas, Y.A., Savitsky, A. P., Zaraisky, A. G., Markelov, M. L., \& Lukyanov, S. A. (1999). Fluorescent proteins from non-bioluminescent Anthozoa species. Nature Biotechnology, 17, 969-973.

Michielse, C. B., Hooykaas, P. J., van den Hondel, C. A., \& Ram A. F. (2005). Agrobacterium-mediated transformation as a tool for functional genomics in fungi. Current Genetics, 48, 1-17.

Molbak, L., Molin, S., \& Kroer, N. (2006). Root growth and exudate production define the frequency of horizontal plasmid transfer in the rhizosphere. FEMS Microbiology Ecology, 59, 167-176.

Newman, K. L., Almeida, R. P., Purcell, A. H., \& Lindow, S. E. (2003). Use of a green fluorescent strain for analysis of Xylella fastidiosa colonization of Vitis vinifera. Applied and Environmental Microbiology, 69, 7319-7327.

Ramos, H. J., Roncato-Maccari, L. D., Souza, F. M., SoaresRamos, J. R., Hungria, M., \& Pedrosa, F. O. (2002). Monitoring Azospirillum-wheat interactions using the $g f p$ and gusA genes constitutively expressed from a new broad-host range vector. Journal of Biotechnology, 97, 243-252.

Ramos, C., Molbak, L., \& Molin, S. (2000). Bacterial activity in the rhizosphere analyzed at the single-cell level by monitoring ribosome contents and synthesis rates. Applied and Environmental Microbiology, 66, 801-809.

Rediers, H., Rainey, P. B., Vanderleyden, J., \& De Mot, R. (2005). Unraveling the secret lives of bacteria: Use of in vivo expression technology and differential fluorescence induction promoter traps as tools for exploring niche specific gene expression. Microbiology and Molecular Biology Reviews, 69, 217-261.

Rothballer, M., Schmid, M., Fekete, A., \& Hartmann, A. (2005). Comparative in situ analysis of ipdC-gfpmut 3 promoter fusions of Azospirillum brasilense strains Sp7 and Sp245. Environmental Microbiology, 7, 1839-1846.

Shaner, N. C., Campbell, R. E., Steinbach, P. A., Giepmans, B. N. G., Palmer, A. E., \& Tsien, R. Y. (2004). Improved monomeric red, orange and yellow fluorescent proteins derived from Discosoma sp. red fluorescent protein. Nature Biotechnology, 22, 1567-1572.

Sörensen, M., Lippuner, C., Kaiser, T., Misslitz, A., Aebischer, T., \& Bumann, D. (2003). Rapidly maturing red fluorescent protein variants with strongly enhanced brightness in bacteria. FEBS Letters, 552, 110-114.

Steidle, A., Sigl, K., Schuhegger, R., Ihring, A., Schmid, M., Gantner, S., Stoffels, M., Riedel, K., Givskov, M., Hartman, A., Langebartels, C., \& Eberl, L. (2001). Visualisation of $\mathrm{N}$-acylhomoserine lactone-mediated cellcell communication between bacteria colonizing the tomato rhizosphere. Applied and Environmental Microbiology, 67, 5761-5770.

Stuurman, N., Pacios Bras, C., Schlaman, C. H. R. M., Wijfjes, A. H. M., Bloemberg, G. V., \& Spaink, H. P. (2000). The use of GFP color variants expressed on stable broad-host range vectors to visualize rhizobia interacting with plants. Molecular Plant-Microbe Interactions, 13, 1063-1069.

Tombolini, R., Unge, A., Davey, M. E., de Bruijn, F. J., \& Jansson, J. K. (1997). Flow cytometric and microscopic 
analysis of GFP-tagged Pseudomonas fluorescens bacteria. FEMS Microbiology Ecology, 22, 17-28.

Tombolini, R., van der Gaag, D. J., Gerhardson, B., \& Jansson, J. K. (1999). Colonization pattern of the biocontrol strain Pseudomonas chlororaphis MA342 on barley seeds visualized by using green fluorescent protein. Applied and Environmental Microbiology, 65, 3674-3680.

Tsien, R. Y. (1998). The green fluorescent protein. Annual Reviews of Biochemistry, 67, 509-544.

Unge, A., Tombolini, R., Moller, A., \& Jansson, J. K. (1997). Optimization of GFP as a marker for detection of bacteria in environmental samples. In: J. W. Hastings, L. J. Kricka \& P. E. Stanley (Eds.). 9th International Symposium on bioluminescence and chemiluminescence: Proceedings volume: Bioluminescence and Chemiluminescence: Molecular Reporting With Photons.

Unge, A., Tombolini, R., Molbak, L., \& Jansson, J. K. (1999). Simultaneous monitoring of cell number and metabolic activity of specific bacterial populations with a dual
gfp-luxAB marker system. Applied and Environmental Microbiology, 65, 813-821.

Unge, A., \& Jansson, J. K. (2001). Monitoring population size, activity, and distribution of $g f p$-luxAB-tagged Pseudomonas fluorescens SBW25 during colonization of wheat. Microbiology Ecology, 41, 290-300.

Utermark, J., \& Karlovsky, P. (2006). Quantification of green fluorescent protein fluorescence using real-time PCR thermal cycler. Biotechniques, 41, 150-154.

Xi, C., Lambrecht, M., Vanderleyden, J., \& Michiels, J. (1999). Bi-functional $g f p$ - and gusA-containing mini-Tn5 transposon derivatives for combined gene expression and bacterial localization studies. Journal of Microbiological Methods, 35, 85-92.

Yang, T. T., Sina, P., Green, G., Kitts, P. A., Chen, Y. T., Lybarger, L., Chervenak, R., Patterson, G. H., Piston, D. W., \& Kain, S. R. (1998). Improved fluorescence and dual color detection with enhanced blue and green variants of the green fluorescent protein. Journal of Biological Chemistry, 273, 8212-8216. 